Для цитирования: Маркова Е.В., Савкин И.В., Княжева М.А., Шушпанова Т.В. Антиконвульсант с иммуномодулирующими свойствами в терапии алкоголизма: экспериментальное исследование. Сибирский вестник психиатрии и наркологии. 2020; 1 (106): 14-22. https://doi.org/10.26617/1810-3111-2020-1(106)-14-22

\title{
Антиконвульсант с иммуномодулирующими свойствами в терапии алкоголизма: экспериментальное исследование
}

\author{
Маркова Е.В. ${ }^{1,2}$, Савкин И.В.', Княжева М.А. ${ }^{1}$, Шушпанова Т.В. ${ }^{3}$ \\ ${ }^{1}$ Научно-исследовательский институт фундаментальной и клинической иммунологии \\ Россия, 630099, Новосибирск, ул. Ядринцевская, д. 14 \\ ${ }^{2}$ Новосибирский государственный педагогический университет \\ Россия, 630126, Новосибирск, ул. Вилюйская, 28 \\ ${ }^{3}$ НИИ психического здоровья, Томский национальный исследовательский медицинский центр \\ Российской академии наук \\ Россия, 634014, Томск, ул. Алеутская, 4
}

\section{PEЗЮME}

Введение: согласно современным представлениям, алкоголизм представляет собой комплексное нарушение гомеостаза организма с нейроиммунными механизмами в патогенезе, что обусловливает перспективность поиска новых эффективных и безопасных фармакологических средств коррекции, обладающих нейроиммуномодулирующим эффектом. Материал и методы: исследование выполнено на мышах-самцах (CBAxC57Bl/6)F1 с активным и пассивным типами поведения. Животным в состоянии экспериментального алкоголизма проводилось курсовое (10 дней) внутрижелудочное введение оригинального соединения мхБГМ. Ориентировочно-исследовательское поведение (ОИП) животных оценивали в тесте «открытое поле». Для оценки интенсивности основных звеньев иммунного ответа мышей иммунизировали посредством внутрибрюшинного введения эритроцитов барана. Гуморальный иммунный ответ оценивали по количеству локальных зон гемолиза в полужидкой среде. Клеточный иммунный ответ оценивали по интенсивности реакции гиперчувствительности замедленного типа. Статистическая обработка результатов проводилась с применением парного критерия Манна-Уитни. Результаты: анализ поведения в тесте «открытое поле» мышей

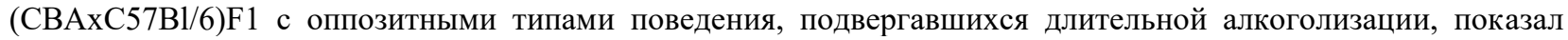
снижение параметров моторного и исследовательского компонентов ОИП у всех животных. После курсового приема м-хБГМ выявлено повышение уровня ОИП у этих мышей, выражающееся в стимуляции моторного и исследовательского компонентов поведения. Анализ показателей интенсивности звеньев иммунного ответа после курсового приема м-хБГМ выявил стимуляцию гуморального иммунного ответа, оцененного по относительному числу антителообразующих клеток селезенки. Наблюдались индивидуально-типологические особенности реагирования животных в состоянии хронического алкоголизма на введение м-хБГМ: эффект был наиболее выражен у животных с активным типом ОИП по сравнению с мышами с пассивным типом поведения. После приема м-хБГМ у всех мышей регистрировалось также существенное повышение уровня развиваемой реакции гиперчувствительности замедленного типа. Стимулирующий клеточное звено иммунного ответа при хронической алкогольной интоксикации эффект м-хБГМ наиболее выражен у животных с пассивным типом ОИП. Заключение: индивидуально-типологические особенности психонейроиммуномодулирующего эффекта оригинального антиконвульсанта при экспериментальном алкоголизме послужат экспериментальным обоснованием дифференцированного использования антиконвульсанта в терапии алкоголизма с позиций персонифицированной медицины.

Ключевые слова: антиконвульсант, алкогольная мотивация, поведение, иммунитет.

\section{ВВЕДЕНИЕ}

Алкоголизм представляет собой глобальную медико-социальную проблему современного общества: в течение последних десятилетий во всем мире, в том числе и в России, сохраняется тенденция к увеличению потребления алкоголя, что приводит к значительному увеличению численности больных алкоголизмом и росту связанных с этим соматических заболеваний [1,
2]. Существенным звеном в патогенезе болезней зависимости является нарушение механизмов нейроиммунного взаимодействия, характеризующееся дисбалансом нейромедиаторов и нейромодуляторов в центральной нервной системе, усиленной продукцией аутоантител к нейромедиаторам, нарушением центральной и периферической продукции цитокинов $[3,4,5$, $6]$. 
Одной из ведущих проблем в лечении алкоголизма является необходимость формирования новых подходов к профилактике и лечению этого заболевания. Перспективным является поиск новых эффективных и безопасных фармакологических средств коррекции, действующих на молекулярные мишени влияния алкоголя в ЦНС и способных корригировать нейроиммунную дизрегуляцию. Мишенями действия алкоголя в центральной нервной системе (ЦНС) являются ГАМКА-рецепторы (ГАМКАР), представляющие основную ингибиторную нейротрансмиттерную систему в ЦНС и играющие центральную роль в опосредовании эффектов этанола [7]. Хроническое употребление алкоголя вызывает также нейроадаптивные изменения бензодиазепиновых рецепторов (БДР), модулирующих ГАМКА-Р, что поддерживает аддиктивное состояние [8].

Модулирующее действие на бензодиазепиновые рецепторы показано для оригинального соединения мета-хлор-бензгидрилмочевины (мхБГМ), синтезированного в Проблемной научно-исследовательской лаборатории синтеза лекарственных средств Томского политехнического университета в процессе поиска высокоэффективных антиконвульсантов [8, 9]. В отличие от большинства аналогов, соединение является действующим веществом, не требующим трансформации в печени, что значительно снижает токсичность и исключает побочные эффекты (сонливость, гепато- и нейротоксические эффекты), что предполагает перспективность его применения в терапии алкоголизма и обусловливает целесообразность исследования влияния данного соединения на психофизиологические показатели животных с алкогольной зависимостью.

\section{ЦЕЛЬ ИССЛЕДОВАНИЯ}

Изучение влияния оригинального антиконвульсанта м-хБГМ на поведенческий паттерн и иммунный ответ у животных с оппозитными типами поведения в состоянии экспериментального алкоголизма.

\section{МАТЕРИАЛЫ И МЕТОДЫ}

Исследование выполнено на мышах-самцах (CBAxC57B1/6)F1 ( $\mathrm{n}=110)$, полученных из лаборатории экспериментальных животных НИИФФМ (Новосибирск) и из питомника НИИ фармакологии и регенеративной медицины им. Е.Д. Гольдберга Томского НИМЦ РАН (Томск). Животных содержали в условиях лабораторного вивария в клетках, по 10 особей в каждой, на стандартной диете, при нормальном световом режиме.
Содержание экспериментальных животных соответствовало правилам, принятым Европейской конвенцией по защите животных, используемых для экспериментальных и иных научных целей (Страсбург, 1986), и правилам лабораторной практики (приказ Министерства здравоохранения Российской Федерации № 267от 19.06.2003).

Экспериментальный алкоголизм был сформирован у мышей-самцов (CBAxC57Bl/6)F1 двух групп - с активным и пассивным типами ОИП путем принудительной алкоголизации (10\% раствор этанола в качестве единственного источника жидкости) в течение 6 месяцев с регулярным замером потребляемого количества раствора этанола. Животным в состоянии экспериментального алкоголизма проводилось курсовое (10 дней) внутрижелудочное введение оригинального соединения м-хБГМ в виде суспензии на $1 \%$ крахмальной слизи в действующей концентрации 11,6 мг/кг в сутки в условиях свободного выбора между $10 \%$ раствором этанола и водой в течение 10 суток (двухбутылочный оральный тест) с ежедневным замером потребления жидкостей каждым животным.

Ориентировочно-исследовательское поведение животных оценивали в тесте «открытое поле», как это было описано ранее $[10,11,12]$ трижды: перед началом алкоголизации, через 6 месяцев принудительной алкоголизации до и после курсового введения м-хБГМ.

Для оценки интенсивности основных звеньев иммунного ответа мышей иммунизировали посредством внутрибрюшинного введения эритроцитов барана $(5 \%-0,5$ мл). Гуморальный иммунный ответ оценивали на пятые сутки после иммунизации по количеству локальных зон гемолиза в полужидкой среде. Определение количества антителообразующих клеток селезенки (АОК) проводилось модифицированным методом A.J. Cunningham [9]. Клеточный иммунный ответ оценивали по интенсивности реакции гиперчувствительности замедленного типа (ГЗТ). Для этого через 96 часов после иммунизации внутрибрюшинным введением эритроцитов барана $(0,5 \%-0,5$ мл) вводили разрешающую дозу указанного антигена (50\% - 0,05 мл) под апоневроз задней стопы. Высоту реакции ГЗТ оценивали через 24 часа после разрешающей инъекции по степени опухания лапы (изменения её толщины по сравнению с позитивно-контрольной задней лапой того же животного, в которую была введена среда RPMI 1640). 
Индекс реакции (ИР) определяли для каждой мыши по формуле: ИР $=($ Ро - Рк $) /$ Рк и выражали в процентах [14].

Статистическая обработка результатов проводилась с применением парного критерия Манна-Уитни (компьютерная программа STATISTICA 10.0 for Windows, StatSoft, USA). Данные представлены в виде $\mathrm{M} \pm \mathrm{SD}$. Различия считали достоверными при $\mathrm{p} \leq 0,05$.

\section{РЕЗУЛЬТАТЫ}

Исследование изменчивости предпочтения этанола лабораторными животными представляет значительный интерес в связи с изучением биологических основ формирования алкогольной мотивации и алкогольной зависимости, а также для разработки и испытания лекарственных средств, снижающих влечение к алкоголю. Длительной алкоголизации были подвергнуты две группы мышей (CBAxC57Bl/6)F1 с активным и пассивным типами ОИП, поскольку ранее нами была показана различная чувствительность указанных групп животных к ПАВ $[10,11,12,15]$. Обнаружено, что животные с пассивным типом поведения потребляли большее количество алкоголя, чем мыши с оппозитным типом поведения: среднесуточное потребление $10 \%$ раствора этанола (мл/мышь) животными указанных групп составило $2,5 \pm 0,5$ и $1,9 \pm 0,65$ соответственно $(\mathrm{p} \leq 0,05)$.

На фоне приема м-хБГМ у всех мышей при экспериментальном алкоголизме, независимо от типа поведения, регистрировалось снижение количества потребляемого раствора этанола и повышение потребления воды в условиях свободного выбора. После 4 дней приема мхБГМ все мыши обеих экспериментальных групп отказались от приема алкоголя.

Представленные результаты свидетельствуют о том, что указанный оригинальный анти- конвульсант при экспериментальном алкоголизме обладает выраженным эффектом, направленным на снижение патологического влечения к алкоголю.

В ходе многочисленных экспериментов, направленных на изучение особенностей исследовательского поведения людей и животных, неоднократно было доказано, что исследовательское поведение следует рассматривать как неотъемлемое проявление жизненной активности любого живого существа. Исследовательское поведение выполняет важнейшую функцию, предназначенную для развития, которая обеспечивает адаптацию организма к динамичному внешнему окружению, а в конечном итоге является гарантией выживания данного организма и вида в целом. Поисковая активность важна как фактор регулирования психического и соматического здоровья. Хроническая алкогольная интоксикация сопровождается, как известно, формированием депрессивноподобного поведения, в силу чего представляло определенный интерес оценить параметры ОИП у мышей с оппозитными типами поведения, находившихся в состоянии хронического алкоголизма, после курсового приема оригинального антиконвульсанта, снижающего влечение к этанолу.

Анализ поведения в тесте «открытое поле» мышей (CBAxC57Bl/6)F1, подвергавшихся длительной алкоголизации, с активным и пассивным типами поведения, показал снижение параметров моторной и исследовательской активности у всех животных. После курсового приема м-хБГМ выявлено повышение уровня ОИП у этих мышей, выражающееся в стимуляции моторного и исследовательского компонентов поведения (табл. 1).

\section{Т а б л и ц а 1. Параметры ориентировочно-исследовательского поведения длительно алкоголизированных мышей (CBAхC57BI/6)F1 с оппозитными типами поведения в тесте «открытое поле» до и после приема м-хБГМ $(\mathrm{M} \pm \mathrm{SD})$}

\begin{tabular}{|c|c|c|c|c|c|c|}
\hline \multirow{2}{*}{$\begin{array}{c}\text { Группа } \\
\text { животных }\end{array}$} & \multicolumn{3}{|c|}{ Горизонтальная двигательная активность } & \multicolumn{3}{|c|}{ Вертикальная двигательная активность } \\
\hline & Периферическая & Центральная & Суммарная & Свободная & С опорой на стенку & Суммарная \\
\hline \multicolumn{7}{|c|}{ Контроль - интактные мыши аналогичного возраста } \\
\hline Активные & $153,2 \pm 21,6$ & $18,1 \pm 2,2$ & $171,3 \pm 24,8$ & $7,1 \pm 3,3$ & $15,4 \pm 5,6$ & $22,5 \pm 9,0$ \\
\hline Пассивные & $36,9 \pm 8,7$ & 0 & $36,9 \pm 8,7$ & 0 & $6,3 \pm 1,5$ & $6,3 \pm 1,5$ \\
\hline \multicolumn{7}{|c|}{ 10\% раствор этанола - длительно (6 месяцев) алкоголизированные мыши } \\
\hline Активные & $90,6 \pm 26,3 *$ & $3,4 \pm 1,2 *$ & $94,0 \pm 26,4^{*}$ & $1,4 \pm 0,2 *$ & $2,5 \pm 1,7 *$ & $3,9 \pm 1,8 *$ \\
\hline Пассивные & $10,1 \pm 2,7 *$ & 0 & $10 \pm 2,7^{*}$ & 0 & $0 *$ & $0 *$ \\
\hline \multicolumn{7}{|c|}{ м-Хбгм - длительно алкоголизированные мыши после курсового введения мета-хлор-бензгидрилмочевины } \\
\hline Активные & $226,2 \pm 37,0 \#^{*}$ & $24,1 \pm 7,7 \#$ & $261,1 \pm 44,1 \#^{*}$ & $17,1 \pm 4,3 \# *$ & $21,4 \pm 8,6 \#$ & $38,5 \pm 1,7 \# *$ \\
\hline Пассивные & $52,1 \pm 4,7 \#^{*}$ & 0 & $52,1 \pm 4,7 \#^{*}$ & $2,1 \pm 0,3 \# *$ & $4,4 \pm 1,6 \#$ & $6,5 \pm 1,7 \#$ \\
\hline
\end{tabular}

П р и м е ч а н и е. $\mathrm{n}=24-28$ в каждой группе. Уровень достоверности: * $-\mathrm{p} \leq 0,05$ по сравнению с контролем; \#-p $\leq 0,05$ по сравнению животными в состоянии экспериментального алкоголизма. 
Выявлены индивидуально-типологические особенности изменения поведенческого паттерна после терапии антиконвульсантом мхБГМ. Так, рост показателей суммарной горизонтальной двигательной активности наиболее выражен у мышей с пассивным типом поведения (в 2,7 раза у активных мышей и в 5,2 раза у пассивных мышей). Причём стимуляция горизонтальной двигательной активности в центральных квадратах поля наблюдалась только у мышей с активным типом поведения. При анализе показателей вертикальной двигательной активности, отражающей исследовательский компонент поведения, установлен значительный стимулирующий эффект м-хБГМ (отмечено повышение суммарной вертикальной активности у мышей с исходно активным типом поведения в 9,6 раза и у животных с пассивным типом поведения в 6,5 раза). При этом у мышей с пассивным типом поведения после приема мхБГМ отмечалось появление не свойственных ранее этим животным свободных стоек. Обращает на себя внимание тот факт, что после приема м-хБГМ большинство параметров поведения длительно алкоголизированных мышей оказались даже выше, чем таковые у интактных животных аналогичного возраста (контрольная группа) и соответствовали параметрам поведения в «открытом поле», характерным для молодых трехмесячных животных.

Анализ показателей интенсивности основных звеньев иммунного ответа после курсового приема м-хБГМ выявил стимуляцию гуморального иммунного ответа, оцененного по относительному числу антителообразующих клеток селезенки. Вместе с тем также наблюдались индивидуально-типологические особенности реагирования животных в состоянии экспериментального алкоголизма на оригинальный антиконвульсант: эффект оказался наиболее выраженным у животных с активным типом ОИП по сравнению с мышами с пассивным типом поведения.

Кроме того, после приема м-хБГМ у всех мышей регистрируется существенное повышение уровня развиваемой реакции гиперчувствительности замедленного типа в ответ на введение Т-зависимого антигена. Стимулирующий клеточное звено иммунного ответа при хронической алкогольной интоксикации эффект мхБГМ оказался наиболее выраженным у животных с пассивным типом ориентировочноисследовательского поведения (в 2 раза сильнее, чем в оппозитной группе).

\section{ОБСУЖДЕНИЕ}

Злоупотребление алкоголем вызывает развитие толерантности и зависимости посредством взаимодействия этанола с ГАМКА/ бензодиазепиновым рецепторным комплексом (ГАМКА/БДР) в разных структурах головного мозга $[7,8,15]$. В литературе описано наличие функциональных ГАМКА-рецепторов на поверхности иммунокомпетентных клеток, изменение активности которых, аналогично эффектам на нейрональных клетках, вызывает модуляцию функциональной активности клеток иммунной системы, преобразуя их пролиферативную активность в периферической крови и костном мозге дозозависимым образом [17, 18, 19, 20]. Посредством ГАМКА-Р показана модуляция интенсивности развития реакции гиперчувствительности замедленного типа $[21,22]$. Ранее исследователями было установлено, что мхБГМ модулирует ГАМКА/БДР в мозге у экспериментальных животных, подвергавшихся длительной алкоголизации, повышая аффинность рецепторов и уровень ГАМК медиации $[8,15,16,23]$; также показана патогенетическая роль изменений в иммунной и нейроэндокринной системах при алкоголизме $[5,6,16,24,25$, $26,27,28]$. Указанные обстоятельства могут являться механизмами психонейроиммуномодулирующего эффекта м-хБГМ, выражающегося в снижении влечения к алкоголю у животных при экспериментальном алкоголизме, стимуляции параметров ОИП и иммунного ответа.

\section{ЗАКЛЮЧЕНИЕ}

Вышеизложенное обусловливает перспективность применения оригинального антиконвульсанта м-хБГМ в терапии алкоголизма. Продемонстрированные индивидуально-типологические особенности реагирования особей с оппозитными типами поведения после длительной алкоголизации на воздействие м-хБГМ послужат экспериментальным обоснованием дифференцированного использования оригинального антиконвульсанта в терапии алкоголизма с позиций персонифицированной медицины.

\section{КОНФЛИКТ ИНТЕРЕСОВ}

Авторы заявляют об отсутствии возможных конфликтов интересов в связи с публикацией данной статьи.

\section{ИСТОЧНИК ФИНАНСИРОВАНИЯ}

Совместная работа выполнена по теме из Плана НИР НИИФКИ (номер госрегистрации 01201356998) и по теме из Плана НИР НИИ психического здоровья Томского НИМЦ РАН (номер госрегистрации AAAA-A19119020690013-2). 


\section{СООТВЕТСТВИЕ ПРИНЦИПАМ ЭТИКИ}

Исследование было проведено с соблюдением норм современной биомедицинской этики и этических стандартов, разработанных в соответствии с Хельсинской декларацией ВМА (Протокол заседания этического комитета НИИФКИ № 106 от 13.04.2018 г.).

\section{ЛИТЕРАТУРА}

1. Бохан Н.А., Мандель А.И., Иванова С.А., Прокопьева В.Д., Артемьев И.А., Невидимова Т.И., Мастерова Е.И., Воеводин И.В., Аболонин А.Ф., Шушпанова Т.В. Старые и новые проблемы наркологии в контексте междисциплинарных исследований. Вопросы наркологии. 2017; 1: 2662. https://elibrary.ru/item.asp?id=30072306

2. Мандель А.И., Артемьев И.А., Ветлугина Т.П., Иванова С.А., Невидимова Т.И., Прокопьева В.Д., Аболонин А.Ф., Шушпанова Т.В. Биологические предикторы, клиникопатогенетические механизмы формирования и профилактика аддиктивных состояний в различных социальных группах (итоги комплексной темы НИР ФГБУ «НИИ ПЗ» СО РАМН, 2009-2012 гг.). Сибирский вестник психиатрии и наркологии. 2013; 4 (72): 40-48.

3. Cui C., Grandison L., Noronha A. Neuroimmune mechanisms of brain function and alcohol related disorders. Brain, Behavior, and Immunity. 2011. 25: 1-3. doi:10.1016/j.bbi.2011.03.005

4. Kelleya K.W., Dantzer R. Alcoholism and inflammation: Neuroimmunology of behavioral and mood disorders. Brain, Behavior, and Immunity. 2011, 25 (1): 13-20. doi:10.1016/j.bbi.2010.12.013

5. Иванова С.А., Ветлугина Т.П., Бохан Н.А., Эпштейн О.И. Иммунобиология аддиктивных расстройств: механизмы психонейроиммуномодуляции. Сибирский вестник психиатрии и наркологии. 2002; 1 (23): 50-57.

6. Невидимова Т.И., Ветлугина Т.П., Батухтина Е.И., Савочкина Д.Н., Найденова Н.Н., Никитина В.Б., Лобачева О.А., Менявцева Т.А., Иванова С.А., Бохан Н.А. Особенности продукции цитокинов при болезнях зависимости. Международный журнал прикладных и фундаментальных исследований. 2015; 1(1): 49-51.

7. Centanni S.W., Teppen T., Risher M.L., Fleming R.L., Moss J.L., Acheson S.K., Mulholland P.J., Pandey S.C., Chandler L.J., Swartzwelder H.S. Adolescent alcohol exposure alters GABAA receptor subunit expression in adult hippocampus. Alcohol. Clin. Exp. Res. 2014, 38: 2800-2808. doi:10.1111/acer.12562

8. Shushpanova T.V., Bokhan N.A., Lebedeva Y.F., Solonskii A.V., Udut V.V. The effect of chronic alcohol abuses оп the benzodiazepine receptor system in various areas of the human brain. African $J$ Psychiary. 2016, 19 (3): 1000365 doi: $10.4172 / 2378-5756.1000365$
9. Novozheeva T., Markova E., Shushpanova O., Knyazeva E., Shushpanova T. Optimizing pharmacotherapy of epilepsy by creating new ways of administering of original anticonvulsant metachlorobenzhydryl urea (m-CLBHU). European Psychiatry. 2019, 56: S15.

10. Маркова Е.В. Иммунная система и высшая нервная деятельность. Механизмы нейроиммунных взаимодействий в реализации и регуляции поведенческих реакций. Saarbruken : LAP LAMBERT Academic Publishing, 2012: 268.

11. Гольдина И.А., Маркова Е.В., Гольдин Б.Г., Княжева М.А., Гайдуль К.В. Протекторные свойства экстракта куркумы при этанолиндуцированных нарушениях поведения. Саратовский научно-медицинский журнал. 2017; 13 (1), 131-135.

12. Чухрова М.Г., Дресвянников В.Л., Маркова Е.В. Наркотическая зависимость: современные стратегии исследования. Saint-Louis, Missouri, USA : Publishing House Science and Innovation Center, 2015: 218

13. Cunningham A.J. A method of increased sensitivity for detecting single antibody-forming cells. Nature. 1965 Sep 4; 207(5001): 1106-7. DOI: 10.1038/2071106a0

14. Yoshikai Y., Miake S., Matsumoto T., Nomoto K., Takeya K. Effect of stimulation and blockade of mononuclear phagocyte system on the delayed footpad reaction to SRBC in mice. Immunology. 1979 Nov; 38(3): 577-83.

15. Shushpanova T., Novozheeva T., Solonskii A., Bokhan N., Markova E. Molecular targets of the ethanol and original anticonvulsant in the treatment of alcohol dependence. European Psychiatry. 2017 Apr; 41(Suppl): https://doi.org/10.1016/j.eurpsy.2017.02.325

16. Савкин И.В., Маркова Е.В., Шушпанова Т.В., Новожеева Т.П., Козлов В.А. Влияние антиконвульсанта галодиф на алкогольную мотивацию, рецепторные системы и цитокины в мозге в эксперименте. Российский иммунологический журнал. 2018; 12 (21), 4: 733-735. DOI: $10.31857 / \mathrm{S} 102872210002656-6$

17. Cavalotti D., Artico M., D`Andrea V., Cavalotti C. GABA-transaminase activity in the human thymus after administration of interferon's. Hum. Immunol. 2000, 61: 697-704 doi:10.1016/S01988859(00)00130-0

18. Alam S., Laughton D.L., Walding A., Wolstenholme A.J. Human peripheral blood mononuclear cells express GABAA receptor subunits. $\mathrm{Mol}$ Immunol. 2006 Mar 4; 43(9): 1432-42. doi:10.1016/j.molimm.2005.07.025

19. Idova G., Alperina E.L., Cheido M.A. Contribution of brain dopamine, serotonin and opioid receptors in the mechanisms of neuroimmunomodulation: evidence from pharmacological analysis. Int Immunopharmacol. 2012 Apr; 12(4): 618-25. doi: 10.1016/j.intimp.2012.02.010 
20. Маркова Е.В., Савкин И.В., Шушпанова Т.В., Княжева М.А., Аникеева О.С. Иммуномодулятор. Патент на изобретение № 2691143. Изобретения и полезные модели. Официальный бюллетень федеральной службы по интеллектуальной собственности. 2019, 17.

21. Tian J., Chau C., Hales T.G., Kaufman D.L. GABA receptors mediate inhibition of T-cell responses. J Neuroimmunol. 1999 Apr 1; 96(1): 21-8. doi: 10.1016/S0165-5728(98)00264-1

22. Markova E, Savkin I., Anikeeva O., Shushpanova T. Immunomodulatory effect of original anticonvulsant meta-chloro-benzhydryl-urea in mice with experimental alcoholism. European Psychiatry. 2019, 56(S): 662-663.

23. Shushpanova T.V., Solonskii A.V., Shushpanova O.V. Molecular-Cellular Targets of the Pathogenic Action of Ethanol in the Human Brain in Ontogenesis and the Possibility of Targeted Therapy Aimed at Correcting the Effect of Pathogenic Factors Drug addiction / Edited by F. Zhao, co-edited by M. Li. London, United Kingdom: IntechOpen, 2018: 73102. DOI: 10.5772/intechopen.73333

24. Маркова Е.В., Савкин И.В., Княжева М.А., Шушпанова Т.В. Новожеева Т.П. Психонейроиммуномодулирующее влияние оригинального антиконвульсанта при экспериментальном алкоголизме. Российский иммунологический журнал. 2019; 13 (22), 3: 1217-1223. DOI: $10.31857 / \mathrm{S} 102872210007256-6$
25. Шушпанова Т.В., Мандель А.И., Бохан Н.А., Бадыргы И.О., Новожеева Т.П., Счастный Е.Д., Солонский А.В., Грущенко Н.Ф., Удут В.В., Шушпанова О.В., Маркова Е.В., Князева Е.М. Роль нейроэндокринных факторов в формировании алкогольной зависимости и экологии человека в различных этнических популяциях, новые подходы в терапии. Якутский медицинский журнал. 2019; 4 (68): 113-118. DOI: 10.25789/YMJ.2019.68.32

26. Шушпанова Т.В., Семке В.Я., Солонский А.В., Бохан Н.А., Удут В.В. Бензодиазепиновая рецепторная система мозга человека и крысы при алкогольной аддикции. Журнал неврологии $u$ психиатрии им. С.С. Корсакова. 2014; 114(5): 50-54.

27. Невидимова Т.И., Батухтина Е.И., Ветлугина Т.П., Савочкина Д.Н., Никитина В.Б., Лобачева О.А., Бохан Н.А.. Сопряжённость продукции цитокинов с уровнем гормонов и сенсорными реакциями при формировании зависимости от психоактивных веществ у лиц мужского пола. Бюллетень экспериментальной биологии и медииины. 2015; 159 (6): 744-748.

28. Шушпанова Т.В. Периферические бензодиазепиновые рецепторы как один из специфических маркеров при алкоголизме. Сибирский вестник психиатрии и наркологии. 2008; 1 (48): 84-88.

Поступила в редакцию 11.10.2019 Утверждена к печати 27.01.2020

Маркова Евгения Валерьевна - д.м.н., заведующая лабораторией нейроиммунологии, главный научный сотрудник ФГБНУ «НИИ фундаментальной и клинической иммунологии», профессор ФГБОУ ВО «Новосибирский государственный педагогический университет». Author ID Scopus 35576645100. Author ID РИНЦ 109914. SPIN-код РИНЦ 8439-7310.

Савкин Иван Владимирович - научный сотрудник лаборатории нейроиммунологии ФГБНУ «НИИ фундаментальной и клинической иммунологии». Author ID Scopus 6507473764. Author ID РИНЦ 117121. SPIN-код РИНЦ 8344-4247.

Княжева Мария Александровна - младший научный сотрудник лаборатории нейроиммунологии ФГБНУ «НИИ фундаментальной и клинической иммунологии». Author ID РИНЦ 703313. SPIN-код РИНЦ 8913-3798.

Шушпанова Тамара Владимировна - к.м.н., ведущий научный сотрудник лаборатории клинической психонейроиммунологии и нейробиологии, Научно-исследовательский институт психического здоровья Томского национального исследовательского медицинского центра Российской академии наук. Researcher ID J-28172017. Author ID Scopus 6506299310. ORCID ID 0000-0002-9455-0358. Author ID РИНЦ 79964. SРIN-код РИНЦ 9158-9235.

Маркова Евгения Валерьевна, evgeniya_markova@mail.ru 
For citation: Markova E.V., Savkin I.V., Knyazheva M.A., Shushpanova T.V. Anticonvulsant with immunomodulating properties in alcoholism therapy: experimental study. Siberian Herald of Psychiatry and Addiction Psychiatry. 2020; 1 (106): 14-22. https://doi.org/10.26617/1810-3111-2020-1(106)-14-22

\title{
Anticonvulsant with immunomodulating properties in alcoholism therapy: experimental study
}

\author{
Markova E.V.. ${ }^{1,}$, Savkin I.V.', Knyazheva M.A. ${ }^{1}$, Shushpanova T.V. ${ }^{3}$ \\ ${ }^{1}$ Federal State Budgetary "Scientific Research Institute of the Fundamental and Clinical Immunology" \\ Yadrintsevskaya Street 14, 630099, Novosibirsk, Russian Federation \\ ${ }^{2}$ Federal State Budgetary Educational Institution of Higher Education "Novosibirsk State Pedagogical University" \\ Vilyuiskaya Street 28, 630126, Novosibirsk, Russian Federation \\ ${ }^{3}$ Mental Health Research Institute, Tomsk National Research Medical Center, Russian Academy of Sciences \\ Aleutskaya Street 4, 634014, Tomsk, Russian Federation
}

\begin{abstract}
Introduction: according to modern concepts, alcoholism is a complex disturbance of the body's homeostasis with neuroimmune mechanisms in pathogenesis, which makes it possible to seek for new effective and safe pharmacological correction agents with a neuroimmunomodulating effect. Material and Methods: the study was performed on male mice (CBAxC57Bl/6)F1 with active and passive behavioral types. Animals in the state of experimental alcoholism underwent a course (10 days) of intragastric administration of the original compound m-chBHU. The exploratory behavior (EB) of animals was evaluated in the "open field" test. To assess the intensity of the immune response mice were immunized by intraperitoneal injection of sheep red blood cells. The humoral immune response was evaluated by the number of local hemolysis zones in a semi-liquid medium. The cellular immune response was evaluated by the intensity of the delayed-type hypersensitivity reaction. Statistical processing of the results was carried out using the paired Mann-Whitney test. Results: analysis of the behavior in the open field test of mice with opposite behavioral types exposed to prolonged alcoholization showed a decrease in the parameters of motor and exploratory activities in all animals. After a course of $\mathrm{m}-\mathrm{hBHU}$ administration, a behavior stimulation in these mice was revealed, which was expressed in stimulation of the motor and investigative components of EB. The analysis of the immune response intensity indicators after a course of $\mathrm{m}$-chBHU administration revealed a stimulation of the humoral immune response, estimated by the relative number of the spleen antibody-forming cells. Individually typological features of the response of animals in the state of chronic alcoholism to the administration of m-chBHU were observed: the effect was most pronounced in animals with an active type of EB compared with mice with a passive type of behavior. After receiving $\mathrm{m}$-chBHU, all mice also showed a significant increase in the level of the developed delayed-type hypersensitivity reaction. The cellular immune response stimulating after $\mathrm{m}$-BHU administration in mice with chronic alcohol intoxication was most pronounced in animals with a passive type of EB. Conclusion: the individual typological features of the original anticonvulsant psychoneuroimmunomodulatory effect in experimental alcoholism will serve as an experimental justification for the differentiated use of the anticonvulsant in the treatment of alcoholism from the standpoint of personalized medicine.
\end{abstract}

Keywords: anticonvulsant, alcoholic motivation, behavior, immunity.

\section{REFERENCES}

1. Bokhan N.A., Mandel A.I., Ivanova S.A., Prokopieva V.D., Artemyev I.A., Nevidimova T.I., Masterova E.I., Voevodin I.V., Abolonin A.F., Shushpanova T.V. Staryye i novyye problemy narkologii v kontekste mezhdistsiplinarnykh issledovaniy [Old and new problems of narcology in the context of interdisciplinary research]. Voprosy narkologii - Journal of Addiction Issues. 2017; 1: 26-62. https://elibrary.ru/item.asp?id=30072306 (in Russian).

2. Mandel A.I., Artemyev I.A., Vetlugina T.P., Ivanova S.A., Nevidimova T.I., Prokopieva V.D., Abolonin A.F., Shushpanova T.V. Biologicheskiye prediktory, kliniko-patogeneticheskiye mekhaniz- my formirovaniya i profilaktika addiktivnykh sostoyaniy $\mathrm{v}$ razlichnykh sotsial'nykh gruppakh (itogi kompleksnoy temy NIR NII psikhicheskogo zdorov'ya Sibirskogo otdeleniya RAMN, 2009-2012 gody) [Biological predictors, clinical and pathogenetic mechanisms of the formation and prevention of addictive states in various social groups (the results of the complex topic of the Scientific Research Institute of Mental Health of the Siberian Branch of the Russian Academy of Medical Sciences, 2009-2012)]. Sibirskiy vestnik psikhiatrii $i$ narkologii - Siberian Herald of Psychiatry and Addiction Psychiatry. 2013; 4 (72): 40-48 (in Russian). 
3. Cui C., Grandison L., Noronha A. Neuroimmune mechanisms of brain function and alcohol related disorders. Brain, Behavior, and Immunity. 2011. 25: 1-3. doi:10.1016/j.bbi.2011.03.005

4. Kelleya K.W., Dantzer R. Alcoholism and inflammation: Neuroimmunology of behavioral and mood disorders. Brain, Behavior, and Immunity. 2011, 25 (1): 13-20. doi:10.1016/j.bbi.2010.12.013

5. Ivanova S.A., Vetlugina T.P., Bokhan N.A., Epstein O.I. Immunobiologiya addiktivnykh rasstroystv: mekhanizmy psikhoneyroimmunomodulyatsii [Immunobiology of addictive disorders: psychoneuroimmunomodulation mechanisms]. Sibirskiy vestnik psikhiatrii i narkologii - Siberian Herald of Psychiatry and Addiction Psychiatry. 2002; 1 (23): 50-57 (in Russian).

6. Nevidimova T.I., Vetlugina T.P., Batukhtina E.I., Savochkina D.N., Naydenova N.N., Nikitina V.B., Lobacheva O.A., Menyavtseva T.A., Ivanova S.A., Bokhan N.A. Osobennosti produktsii tsitokinov pri boleznyakh zavisimosti [Features of the production of cytokines in addiction diseases]. Mezhdunarodnyy zhurnal prikladnykh i fundamental'nykh issledovaniy - International Journal of Applied and Basic Research. 2015; 1(1): 49-51 (in Russian).

7. Centanni S.W., Teppen T., Risher M.L., Fleming R.L., Moss J.L., Acheson S.K., Mulholland P.J., Pandey S.C., Chandler L.J., Swartzwelder H.S. Adolescent alcohol exposure alters GABAA receptor subunit expression in adult hippocampus. Alcohol. Clin. Exp. Res. 2014, 38: 2800-2808. doi:10.1111/acer.12562

8. Shushpanova T.V., Bokhan N.A., Lebedeva Y.F., Solonskii A.V., Udut V.V. The effect of chronic alcohol abuse oп the benzodiazepine receptor system in various areas of the human brain. African J Psychiary. 2016, 19 (3): 1000365 doi: 10.4172/23785756.1000365

9. Novozheeva T., Markova E., Shushpanova O., Knyazeva E., Shushpanova T. Optimizing pharmacotherapy of epilepsy by creating new ways of administering of original anticonvulsant metachlorobenzhydryl urea (m-CLBHU). European Psychiatry. 2019, 56: S15.

10. Markova E.V. Immunnaya sistema i vysshaya nervnaya deyatel'nost'. Mekhanizmy neyroimmunnykh vzaimodeystviy $\mathrm{v}$ realizatsii i regulyatsii povedencheskikh reaktsiy [The immune system and higher nervous activity. The mechanisms of neuroimmune interactions in the implementation and regulation of behavioral reactions]. Saarbruken : LAP LAMBERT Academic Publishing, 2012: 268 (in Russian).

11. Goldina I.A., Markova E.V., Goldin B.G., Knyazheva M.A., Gaidul K.V. Protektornyye svoystva ekstrakta kurkumy pri etanolindutsirovannykh narusheniyakh povedeniya. [Protective properties of turmeric extract in ethanol-induced behavioral disorders]. Saratovskiy nauchno-meditsinskiy zhur- nal - Saratov Journal of Medical Scientific Research. 2017; 13 (1), 131-135 (in Russian).

12. Chukhrova M.G., Dresvyannikov V.L., Markova E.V. Narkoticheskaya zavisimost': sovremennyye strategii issledovaniya [Drug Addiction: Current Research Strategies]. Saint-Louis, Missouri, USA : Publishing House Science and Innovation Center, 2015: 218 (in Russian).

13. Cunningham A.J. A method of increased sensitivity for detecting single antibody-forming cells. Nature. 1965 Sep 4; 207(5001): 1106-7. DOI: $10.1038 / 2071106 a 0$

14. Yoshikai Y., Miake S., Matsumoto T., Nomoto K., Takeya K. Effect of stimulation and blockade of mononuclear phagocyte system on the delayed footpad reaction to SRBC in mice. Immunology. 1979 Nov; 38(3): 577-83.

15. Shushpanova T., Novozheeva T., Solonskii A., Bokhan N., Markova E. Molecular targets of the ethanol and original anticonvulsant in the treatment of alcohol dependence. European Psychiatry. 2017 Apr; 41(Suppl): https://doi.org/10.1016/j.eurpsy.2017.02.325

16. Savkin I.V., Markova E.V., Shushpanova T.V., Novozheeva T.P., Kozlov V.A. Vliyaniye antikonvul'santa galodif na alkogol'nuyu motivatsiyu, retseptornyye sistemy i tsitokiny $\mathrm{v}$ mozge $\mathrm{v}$ eksperimente. [The effect of the anticonvulsant halodif on alcohol motivation, receptor systems and cytokines in the brain in the experiment]. Rossiyskiy immunologicheskiy zhurnal - Russian Immunological Journal. 2018; $12 \quad$ (21), 4: 733-735. DOI: $10.31857 / \mathrm{S} 102872210002656-6$ (in Russian).

17. Cavalotti D., Artico M., D`Andrea V., Cavalotti C. GABA-transaminase activity in the human thymus after administration of interferon's. Hum. Immunol. 2000, 61: 697-704. doi:10.1016/S01988859(00)00130-0

18. Alam S., Laughton D.L., Walding A., Wolstenholme A.J. Human peripheral blood mononuclear cells express GABAA receptor subunits. Mol Immunol. 2006 Mar 4; 43(9): 1432-42. doi:10.1016/j.molimm.2005.07.025

19. Idova G., Alperina E.L., Cheido M.A. Contribution of brain dopamine, serotonin and opioid receptors in the mechanisms of neuroimmunomodulation: evidence from pharmacological analysis. Int Immunopharmacol. 2012 Apr; 12(4): 618-25. doi: 10.1016/j.intimp.2012.02.010

20. Markova E.V., Savkin I.V., Shushpanova T.V., Knyazheva M.A., Anikeeva O.S. Immunomodulator. Patent na izobretenie No. 2691143 [Immunomodulator. Patent for invention No. 2691143]. Inventions and utility models. Official Bulletin of the Federal Service for Intellectual Property. 2019, 17 (in Russian).

21. Tian J., Chau C., Hales T.G., Kaufman D.L. GABA receptors mediate inhibition of T-cell responses. J Neuroimmunol. 1999 Apr 1; 96(1): 21-8. doi: 10.1016/S0165-5728(98)00264-1 
22. Markova E, Savkin I., Anikeeva O., Shushpanova T. Immunomodulatory effect of original anticonvulsant meta-chloro-benzhydryl-urea in mice with experimental alcoholism. European Psychiatry. 2019, 56(Suppl): S 662-663.

23. Shushpanova T.V., Solonskii A.V., Shushpanova O.V. Molecular-Cellular Targets of the Pathogenic Action of Ethanol in the Human Brain in Ontogenesis and the Possibility of Targeted Therapy Aimed at Correcting the Effect of Pathogenic Factors Drug addiction / Edited by F. Zhao, co-edited by M. Li. London, United Kingdom: IntechOpen, 2018: 73 102. DOI: 10.5772/intechopen.73333

24. Markova E.V., Savkin I.V., Knyazheva M.A., Shushpanova T.V., Novozheeva T.P. Psikhoneiroimmunomoduliruiushchee vliyaniye originalnogo antikonvulsanta pri eksperimentalnom alkogolizme [Psychoneuroimmunomodulatory effects of the original anticonvulsant at experimental alcoholism]. Rossiyskiy immunologicheskiy zhurnal - Russian Immunological Journal. 2019; 13 (22), 3: 1217 1223. DOI: $10.31857 / \mathrm{S} 102872210007256-6$ (in Russian).

25. Shushpanova T.V., Mandel A.I., Bokhan N.A., Badirgy I.O., Novozheeva T.P., Schastnyy E.D., Solonskiy A.V., Grushchenko N.F., Udut V.V., Shushpanova O.V., Markova E.V., Knyazeva E.M. Rol' neyroendokrinnykh faktorov $\mathrm{v}$ formirovanii alkogol'noy zavisimosti i ekologii cheloveka v razlichnykh etnicheskikh populyatsiyakh, novyye podkhody $\mathrm{v}$ terapii [The role of neuroendocrine factors in the formation of alcohol dependence and human ecology in various ethnic populations, new approaches to therapy]. Yakutskiy meditsinskiy zhurnal - Yakut Medical Journal. 2019; 4 (68): 113-118. DOI: 10.25789/YMJ.2019.68.32 (in Russian).

26. Shushpanova T.V., Semke V.Ya., Solonskiy A.V., Bokhan N.A., Udut V.V. Benzodiazepinovaya retseptornaya sistema mozga cheloveka i krysy pri alkogol'noy addiktsii [Benzodiazepine receptor system of the human brain and rat brain during alcohol addiction]. Zhurnal nevrologii i psikhiatrii im. S.S. Korsakova - S.S. Korsakov Journal of Neurology and Psychiatry. 2014; 114(5): 50-54 (in Russian).

27. Nevidimova T.I., Batukhtina E.I., Vetlugina T.P., Savochkina D.N., Nikitina V.B., Lobacheva O.A., Bokhan N.A. Sopryazhonnost' produktsii tsitokinov s urovnem gormonov i sensornymi reaktsiyami pri formirovanii zavisimosti ot psikhoaktivnykh veshchestv $u$ lits muzhskogo pola [The correlation of the production of cytokines with the level of hormones and sensory reactions in the formation of dependence on psychoactive substances in males]. Byulleten' eksperimental'noy biologii $i$ meditsiny Bulletin of Experimental Biology and Medicine. 2015; 159 (6): 744-748 (in Russian).

28. Shushpanova T.V. Perifericheskiye benzodiazepinovyye retseptory kak odin iz spetsificheskikh markerov pri alkogolizme [Peripheral benzodiazepine receptors as one of the specific markers for alcoholism]. Sibirskiy vestnik psikhiatrii $i$ narkologii - Siberian Herald of Psychiatry and Addiction Psychiatry. 2008; 1 (48): 84-88 (in Russian).

Received October 11.2019 Accepted January 27.2020

Markova Evgeniya V., - MD, Head of the Neuroimmunology Laboratory, Chief Researcher, Federal State Budgetary Scientific Institution "Scientific Research Institute of the Fundamental and Clinical Immunology", professor, Federal State Budgetary Educational Institution of Higher Education "Novosibirsk State Medical University", Novosibirsk, Russian Federation. Author ID Scopus 35576645100. Author ID RSCI 109914. SPIN-code RSCI 8439-7310.

Savkin Ivan V. - researcher of the Neuroimmunology Laboratory, Federal State Budgetary Scientific Institution "Scientific Research Institute of the Fundamental and Clinical Immunology", Novosibirsk, Russian Federation. Author ID Scopus 6507473764. Author ID RSCI 117121. SPIN-code RSCI 8344-4247.

Knyazheva Maria A. - Junior Researcher of the Neuroimmunology Laboratory, Federal State Budgetary Scientific Institution "Scientific Research Institute of the Fundamental and Clinical Immunology", Novosibirsk, Russian Federation. Author ID RSCI 703313. SPIN-code RSCI 8913-3798.

Shushpanova Tamara V. - PhD, lead researcher, Laboratory of Clinical Psychoneuroimmunology and Neurobiology, Mental Health Research Institute, Tomsk National Research Medical Center, Russian Academy of Sciences, Tomsk, Russian Federation. Author ID Scopus 6506299310. ORCID ID 0000-0002-9455-0358. Author ID RSCI 79964. SPIN-code RSCI 9158-9235.

Markova Evgenia V., evgeniya_markova@mail.ru 